\title{
An Interactive Multimodal Analysis of the Portrayal of Women in TV Detergent Advertisements
}

\author{
By
}

\author{
Amal Zakareya Hal \\ Assistant Lecturer at Faculty of Arts, \\ Port Said University
}

DOI: 10.21608/jfpsu.2021.68522.1055

العقد الثمامن عشر / يوليو - 2021هـ 


\title{
An Interactive Multimodal Analysis of the Portrayal of Women in TV Detergent Advertisements
}

\begin{abstract}
This research investigates the representation of women in TV commercials. It is conducted with the help of an interactive multimodal analysis of two TV detergent advertisements. The major objective of thisresearch is to find out how women are portrayed in both Egyptian and American TV commercials. Under the broad theory of multimodality, the researcher carries out an interactive metafunction analysis of the selected advertisements. This analysis is based on three systems: contact, social distance and attitude. The findings of the researchindicate that the Egyptian advertisement presents a stereotypical image of women. It supports the belief that a woman has to learn how to do the laundry in order to get married. On the contrary, the American commercial shows a positive representation of women. It perpetuates the idea that a woman has to be self-assured and successful at her work.
\end{abstract}

Keywords: women, TV commercials, interactive multimodal analysis, multimodality, social distance, attitude 


\section{تحليل تفاعلي متعدد الأنماط لتصوير المرأة في الإعلانات التليفزيونية لمواد التنظيف}

المستخلص

يتناول هذا البحث تمثيل المرأة في الإعلانات التليفزيونية ويتم اجراؤه بواسطة تحليل تفاعلي متعدد

الأنماط لإعلانين تليفزيونين لمواد التنظيف. والهدف الرئيسي لهذا البحث هو معرفة كيفية تصوير المرأة في كلٍ من الإعلانات التليفزيونية المصرية والأمريكية. ففي إطار نظرية تعدد الأنماط تقوم الباحثة بإجراء

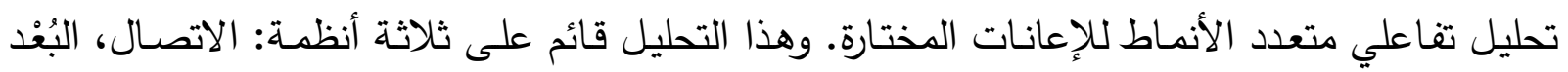
الاجتماعي ، الاتجاه. توضـح نتائج البحث أن الإعـلان المصـري يقدم صـورة نمطية للمرأة حيث يُدعم

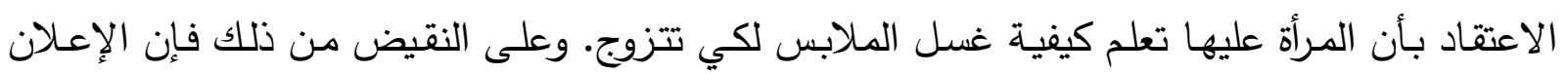
الأمريكي يُعرض صورة ايجابية للمرأة حيث يُرسخ فكرة أن المرأة عليها أن تكون واثقة من نفسئ ونسا وناجحة في عملها.

الكلمـات المفتاحيـة: النسـاء ، الإعلانـات التليفزيونيـة ، التحليل التفاعلي متعدد الأنماط ، تعدد الأنماط ، البُعْد الاجتماعي ، الاتجاه 


\section{$\underline{\text { Introduction }}$}

The overwhelming use of women in advertisements needs investigation. TV advertisements, for instance, can reflect the woman's role in society.In this regard, Dyer (2009) maintains that advertising "has become more and more involved in the manipulation of social values and attitudes, and less concerned with the communication of essential information about goods and services" (p. 1). The current research focuses mainly on the representation of women in detergent TV commercials.

\section{$\underline{\text { Aim of the study }}$}

This research attempts to examine the interactive multimodal representation of women in detergentcommercials which are broadcast in Egypt and America. This study also aims to investigate whether women are positively or negatively represented in the selected advertisements.

\section{$\underline{\text { Research questions }}$}

This research attempts to answer the following questions:

1. How can the interactive multimodal analysis help in indicating the way women are represented in TV commercials?

2. What are the different multimodal resources utilized by advertisers for the same product in the Egyptian and American TV advertisements?

3. Are women positively or negatively portrayed in TV commercials? 


\section{$\underline{\text { Literature review }}$}

\section{Multimodality}

According to Jewitt et al. (2016), the term 'multimodality' was coined in the mid-1990s and developed in the early 2000s. Multimodality originated from Halliday's (1978) work on language as a social semiotic system in which he formulates a theory of language based on a social functional approach of meaning. Halliday sets out a framework for describing language as a system of options, thereby focusing on language as a social system rather than as a linguistic system. Jewitt (2013) defines multimodality as "an interdisciplinary approach drawn from social semiotics that understands communication and representation as more than language and attends systematically to the social interpretation of a range of forms of making meaning" (p. 250). Jewitt et al. (2016) claim that multimodality "highlights that people draw on distinctly different sets of resources for meaning making (e.g. gaze, speech, gesture).... These resources are used in conjunction to form multimodal wholes" (p. 158). As maintained by van Leeuwen (2005), multimodality refers to "[t]he combination of different semiotic modes-for example, language and music-in a communicative artefact or event" (p. 281).

Jewitt (2013) points out that multimodality is based on three interconnected theoretical assumptions. The first assumption is that language is not the starting point of multimodality in that it is a part of a multimodal ensemble. This idea is adopted by Kress (2001) who argues that "communication and representation always draw on a multiplicity of semiotic modes of which language may be one" (pp. 67-68). Kress (2012) claims that a multimodal approach regards language, whether spoken or written, as a means among numerous means available for making meaning. This entails that linguistic modes are partial means of making meaning. In this respect, Kress (2012) asserts that multimodality does not give priority to the linguistic modes including both speech and writing. That is, "any mode can be 'prior' in its use in a particular environment" (p. 46). In the same vein, Jewitt et al. (2016) argue that "multimodality marks a departure from the traditional opposition of 'verbal' and 'non-verbal' communication, which presumes that the verbal is primary and that 
all other means of making meaning can be dealt with by one and the same term" (p. 3).

The second assumption underpinning multimodality is that "all modes have, like language, been shaped through their cultural, historical and social uses to realize social functions as required by different communities" (Jewitt, 2013, p. 251). Consequently, each mode is perceived to be having different semiotic resources or meaning potentials. Multimodality emphasizes the significance of the social context along with the resources which are available for meaning making. That is, it attempts to relate the material semiotic resources utilised by people to what they signify in social contexts. In this regard, Jewitt (2013) asserts that multimodality foregrounds the modal choices which people make in addition to the social effect these choices have on meaning. This refers to the importance of context which shapes the available resources for meaning making.

The third assumption underlying multimodality is that "people orchestrate meaning through their selections and configuration of modes" (Jewitt, 2013, p. 251). This demonstrates the significance of the interaction between modes in the process of making meaning. In other words, the meanings made by any mode are always combined with the meanings of other modes in the communicative ensemble. Thus the interaction between modes constitutes an essential part in the production of meaning. Kress (2010) indicates that using writing, image and colour in one sign, for instance a sign showing the way to a car park of a supermarket, has real benefits since "each mode does a specific thing: image shows what takes too long to read, and writing names what would be difficult to show. Colour is used to highlight specific aspects of the overall message" (p. 1, italics in the original). This indicates that each mode has its distinct potentials for making meaning, and the combination of modes results in a richer meaning which cannot be made by one single mode. In this respect, Kress \& van Leeuwen (2006) maintain that a multimodal text is "a semiotic interplay in which each mode, the verbal and the visual, is given a defined and equal role to play" ( $\mathrm{p}$. 113).

All in all, Jewitt (2013) states that multimodality is an effective approach used for investigating "the modal meaning potentials of a resource... as well as how people make use of these resources in interaction" (p. 256). She adds that 
multimodal studies examine how semiotic resources are utilized to articulate discourses across different types of contexts and media as it is the case with advertisements. Accordingly, Jewitt et al. (2016, p. 3) formulate the following key premises of multimodality:

1. Meaning is made with different semiotic resources, each offering distinct potentialities and limitations.

2. Meaning making involves the production of multimodal wholes.

3. If we want to study meaning, we need to attend to all semiotic resources being used to make a complete whole.

\section{Studies on the representation of women in advertisements}

An example of the studies conducted on gender representation is Abdel Aziz's (2018) research in which she examined how gender representation was redefined in selected TV commercials. Utilising a multimodal approach, Abdel Aziz investigated the use of verbal and visual modes for redefining gender stereotypes in TV commercials. She aimed to illustrate the significance of incorporating verbal and visual modes in conveying meanings related to gender. In addition, she attempted to decode the implicit messages pertaining to gender portrayal in those commercials. The data for Abdel Aziz's study consisted of two commercials which were broadcast on TV in 2017. She downloaded them from the website YouTube.com. In order to analyse those commercials, Abdel Aziz segmented them into excerpts with the help of a software programme QQ Player 3.7.Abdel Aziz carried out a qualitative analysis based on two approaches: Machin and Myer's (2012) multimodal critical discourse analysis, and Norris's (2004) multimodal interactional analysis. Concerning the first approach, Abdel Aziz first explored the lexical choices such as word connotation and structural opposition. Then, she investigated the visual choices such as iconography and attributes. After that, she discussed how these two modes of communication worked together in creating meaning. As to the second approach, Abdel Aziz analysed the two commercials with the help of Norris's (2004) three levels of the action: lower-level action, higher-level action and frozen level action. The results of Abdel Aziz's study showed that there was a tendency towards changing gender stereotypes and gender roles for men and women. This was elaborated 
through the analysis of both verbal and visual communicative modes whose interplay highlighted the idea of the redefinition of gender representation. The analysis also indicated that multimodality contributed to revealing the implicit and explicit messages existing in the investigated commercials.

Relying on a pragmatic perspective, Gómez (2017) examined the roles and images of women in advertising. She aimed to investigate the roles and portrayal of women in the advertisements related to the Western culture. Meanwhile, Gómez focused on the changes in women's depiction between 20th-century and 21 st-century advertisements. She also aimed to highlight the significance of utilising the relevance theory in the analysis of advertising discourse. The data for Gómez's study was composed of ten advertisements from the 20th and 21st centuries. She divided them into pairs which were thematically related to each other. The first pair depicted the female body image. The second pair represented the objectification of female models. The third pair discussed women's inferiority. The fourth pair described devaluation of women. The fifth pair illustrated women's traditional roles.Gómez conducted a pragmatic analysis based on Wilson and Sperber's (2004) relevance theory. She attempted to prove that this theory could be applicable to advertising. That is, a relevance-theoretic perspective could help in revealing the advertisers' intended meaning. Gómez analysed visual advertisements accompanied by texts to show that each item in those advertisements included the advertiser's thoughtful decision to attract the consumers' attention. Throughout her analysis, Gómez concentrated on interpreting the assumptions which were explicitly and implicitly communicated by the chosen advertisements. Moreover, she tried to shed light on the evolution of women's roles and misconceptions in the present and past centuries' advertisements. The findings of Gómez's study showed that 20th-century advertisements conveyed information explicitly whereas 21st-century advertisements communicated information implicitly. Concerning the portrayal of women, the results indicated that contemporary advertisements represented the same stereotypical images of women that existed in the old ones. This portrayal depended mainly on sexism, sexual objectification and traditional archetypes. In this regard, Gómez concluded that those clichéd depictions of women had to end since they were not related to the contemporary society calling for women's rights and gender equality. 


\section{Theoretical framework}

\section{Visual social semiotics}

Drawing on Halliday's social semiotic model of language, Kress \& van Leeuwen (2006) put forward a social semiotic theory of visual communication, thereby establishing a framework for multimodality. They suggest that "visual structures point to particular interpretations of experience and forms of social interaction" (p. 2). Consequently, they assert that visual design can fulfill Halliday's three main metafunctions: ideational, interpersonal and textual. The ideational function represents the world inside and around us; the interpersonal function enacts social interactions as social relations; and the textual function shows coherence in texts. In other words, Kress \& van Leeuwen indicate that "whether we engage in conversation, produce an advertisement or play a piece of music, we are simultaneously communicating, doing something... and representing some aspect of the world..., and we bend these activities together in a coherent text" (p. 15).

Kress \& van Leeuwen's (2006) approach to communication is based mainly on social meanings. They argue that because societies consist of groups with varying interests, the messages conveyed by individuals reflect the differences that characterize social life. In this respect, they state that "the different modes through which texts are constructed show these social differences, so that in a multimodal text using images and writing the writing may carry one set of meanings and the images carry another" (p. 20). For example, in an advertisement the verbal text may be non-sexist, whereas the visual text depicts sexist stereotypes. Moreover, Kress \& van Leeuwen hold the view that both language and visual communication can be utilised to realise the same major systems of meaning which form our cultures-each does so differently through its own specific forms. To put it another way, what language conveys via the choice between different clause structures and word classes can be depicted in visual communication via the choice between various uses of colour and different compositional structures.

In a nutshell, Kress \& van Leeuwen's (2006) view is that "different semiotic modes - the visual, the verbal, the gestural, etc.-each have their 
potentialities and their limitations" (p. 31). Ergo, they propose three kinds of meanings of visual communication in accordance with Halliday's ideational, interpersonal and textual metafunctions. These meaning functions include representational, interactive and compositional metafunctions respectively. Kress \& van Leeuwen postulate that these metafunctions are not only applicable to speech and writing but to all semiotic modes as well. They also emphasize that these metafunctions can be usefully applied to moving images. In the same vein, Jewitt (2013) asserts that multimodality applies these three metafunctions to all modes so as to "better understand their meaning potential- 'what can be meant' or 'what can be done' with a particular set of semiotic resources" (p. 256).

\subsection{The interactive metafunction}

In this metafunction Kress \& van Leeuwen (2006) discuss the resources of visual communication which are used for maintaining the interaction that exists between the producer of the image and its viewer. Images along with any other kinds of visual include represented participants and interactive participants. Therefore, Kress \& van Leeuwen argue that images involve three types of relations: "(1) relations between represented participants; (2) relations between interactive and represented participants (the interactive participants' attitudes towards the represented participants); and (3) relations between interactive participants (the things interactive participants do to or for each other through images)" (p. 114). Accordingly, Jewitt \& Oyama (2004) indicate that images establish special relations between viewers and the world represented within the picture frame. That is, images interact with viewers and hence reflect the attitude which viewers should adopt to what is represented.

All in all, the interactive metafunction deals with the way in which images depict social interactions and social relations. Consequently, Kress \& van Leeuwen suggest three major kinds of realising interactive meanings in images: contact, social distance and attitude.

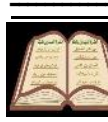




\subsubsection{Contact}

Based on the system of gaze, they categorise images into demand and offer. In a demand image, contact between the represented participant and the viewer is made by means of a vector emanating through the represented participant's eyeline and directed to the viewer. This vector can be accompanied by another vector formed by a gesture pointing at the viewer. In an offer image, the represented participant does not gaze at the viewer so there is no contact between them. In this case, represented participants are detached from the viewer and are depicted as, for instance, pieces of information. Additionally, Kress \& van Leeuwen suggest that the same distinction between demand and offer can be applied to moving images in that "represented participants can turn towards the camera and look at the lens (and hence at the viewer), or can avert their gaze" (p. 264).

\subsubsection{Social distance}

According to Kress \& van Leeuwen (2006), this aspect of the interactive meanings of images is linked to the size of frame which involves "the choice between close-up, medium shot and long shot" (p. 124). That is, producers of images may depict the represented participants as close to viewers or as far away from them. In this regard, the choice of distance can entail various relations between the represented participants and the viewers. Utilising the terms of film and television, Kress \& van Leeuwen describe the size of frame with reference to the human body. They state that the close-up or the close shot displays head and shoulders of the represented participants, whereas the extreme close-up or the very close shot shows anything less than that. As regards the medium close shot, it cuts off the represented participants approximately at the waist; and the medium shot cuts them off nearly at the knees. Pertaining to the medium long shot, it presents the full figure. In the long shot the represented participant fills roughly half the height of the image frame while the very long shot shows anything wider than that. 
Kress \& van Leeuwen (2006) argue that the size of frame reveals the kind of relationships between the represented participants and viewers. They point out that the close shot portrays an intimate or personal relationship, the medium shot suggests a social relationship, and the long shot reflects an impersonal relationship. They further indicate that these relations are imaginary. In other words, people in images are depicted as if they were friends or as if they were strangers. Therefore, images cause viewers to imaginably come close to the represented participants as though they are their friends-or to see them as strangers. In the same vein, Jewitt \& Oyama (2004) emphasise that the close-up shot shows the details of the represented participants' face and expressions, and consequently reveals their personality. In this case, it enables viewers to see the represented participants as they normally see people they are more or less acquainted with.

Relating to close social distance in which the whole figure is seen, Hall (1966) opines that it involves the distance of impersonal business. That is, close social distance is very common for people working together or for those attending a casual social gathering. Thus Hall claims that "[t]o stand and look down at a person at this distance has a domineering effect, as when a man talks to his secretary or receptionist" (p. 121). In respect of far social distance in which the entire figure is shown with space around it, Hall illustrates that it includes the distance people move to if somebody tells them to stand away so as to look at them. He also argues that business and social interaction carried out at this distance are more formal than those conducted at the close social distance. Hence, Hall maintains that far social distance can be used to "insulate or screen people from each other" (p. 123). As cited in Kress \& van Leeuwen (2006), public distance in which the torso of minimally four or five people is seen is the distance kept between people who are strangers and will remain strangers. 


\subsubsection{Attitude}

As maintained by Kress \& van Leeuwen (2006), attitude can be realised by the system of perspective which is another way of creating relations between the represented participants and viewers. Besides, Kress \& van Leeuwen state that perspective implies the selection of an angle or a point of view. Ergo, they distinguish between horizontal and vertical angle. With respect to the horizontal angle, they define it as "a function of the relation between the frontal plane of the image-producer and the frontal plane of the represented participants. The two can either be parallel, aligned with one another, or form an angle, diverge from one another" (p. 134).

Kress \& van Leeuwen (2006) explicate that images photographed with a horizontal angle can be frontal or oblique in terms of the point of view of involvement. Hence, they relate the difference between the frontal and the oblique angle to the difference between involvement and detachment. Kress \& van Leeuwen illustrate that the horizontal angle implies whether the viewer is involved with or detached from the represented participants. On the one hand, the frontal angle suggests that what viewers see in the image is part of their world, something they are involved with. On the other hand, the oblique angle signifies that what viewers see in the image is not part of their world; it is the world of the represented participants, something the viewers are detached from. In this regard, Jewitt \& Oyama (2004) assert that in case of the frontal angle, the viewer is directly confronted by what is represented in the picture, thereby creating maximum involvement. They point out that if something is portrayed from the side, "the viewer literally and figuratively remains on the sidelines" ( $\mathrm{p}$. 135).

As to the vertical angle, Kress \& van Leeuwen (2006) state that it involves the choice between a high angle, a low angle and an eye-level angle in terms of the point of view related to power. They indicate that when a represented participant is photographed from a high angle, the viewer has power over him or her. In case the represented participant is viewed from a low angle, he or she is depicted as exercising power over the viewer. If the image is at eye level, the represented participant and the viewer are on equal terms and there is no difference in power between them. In other words, the high angle signifies the 
power of the viewer; the low angle reflects the power of the represented participant; and the eye-level angle denotes equality between the represented participant and the viewer.

\section{Data of the study}

The corpus of this research consists of two TV commercials downloaded from Youtube.com. The first is an Egyptian commercial advertising Tide laundry detergent. The second is an American commercial about the same product. The researcher has first surfed the internet for the international brands of different categories of products such as laundry detergents. The reason why the researcher has chosen this category is that it is perceived to be closely related to women. In order to be able to analyze the chosen commercials, the researcher has divided each commercial into subsequent shots and picked the most significant ones which help in answering the questions of this study.

\section{$\underline{\text { Sample analysis }}$}

\section{Analysis of Tide Egypt TV commercial}

This commercial advertises a type of a laundry detergent called Tide which is an American brand. The commercial features two female represented participants in a domestic setting: an Egyptian mother and her daughter. The mother seems to be in her early fifties and her daughter seems to be in her twenties. The mother is quite plump while the daughter has got a slim figure. They are both wearing eyeglasses and putting on a little make-up. The mother's garcon haircut along with its colour reflects her being fashionable. Both the mother and her daughter are dressed in trendy casual clothes in bright colours but the mother's outfit looks a bit more formal than her daughter's. Furthermore, the mother looks more organised than her daughter. This appears in her neat hairstyle as well as the watch she is wearing. It is noteworthy that the mother is not depicted as wearing hijab. Besides, some of the shots reveal the tight trousers together with the short 
blouse she is wearing, which is not suitable for her age and body shape according to the culture of the Egyptian society.

$$
\begin{aligned}
& \text { (لا تكوني فاكرة انك } \\
& \text { حتتجوزي وانت ما } \\
& \text { بتعرفيش تغسلي) }
\end{aligned}
$$

(Don't you think that you'll get married if you don't know to

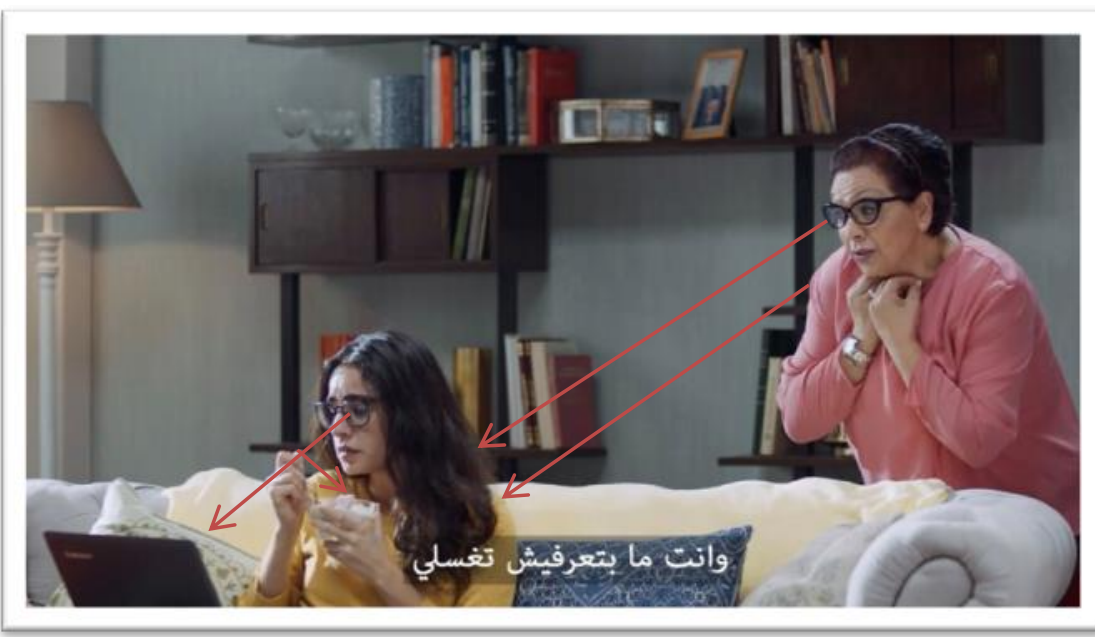

do the washing?)

(البطولة للمسحوق)

(The protagonist

is the detergent)

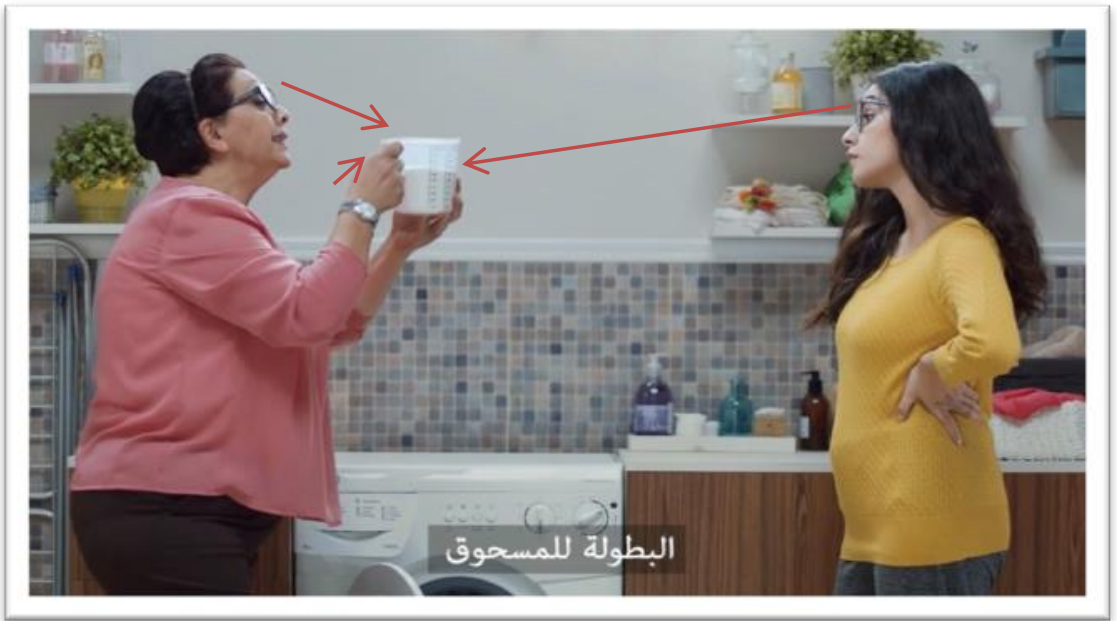




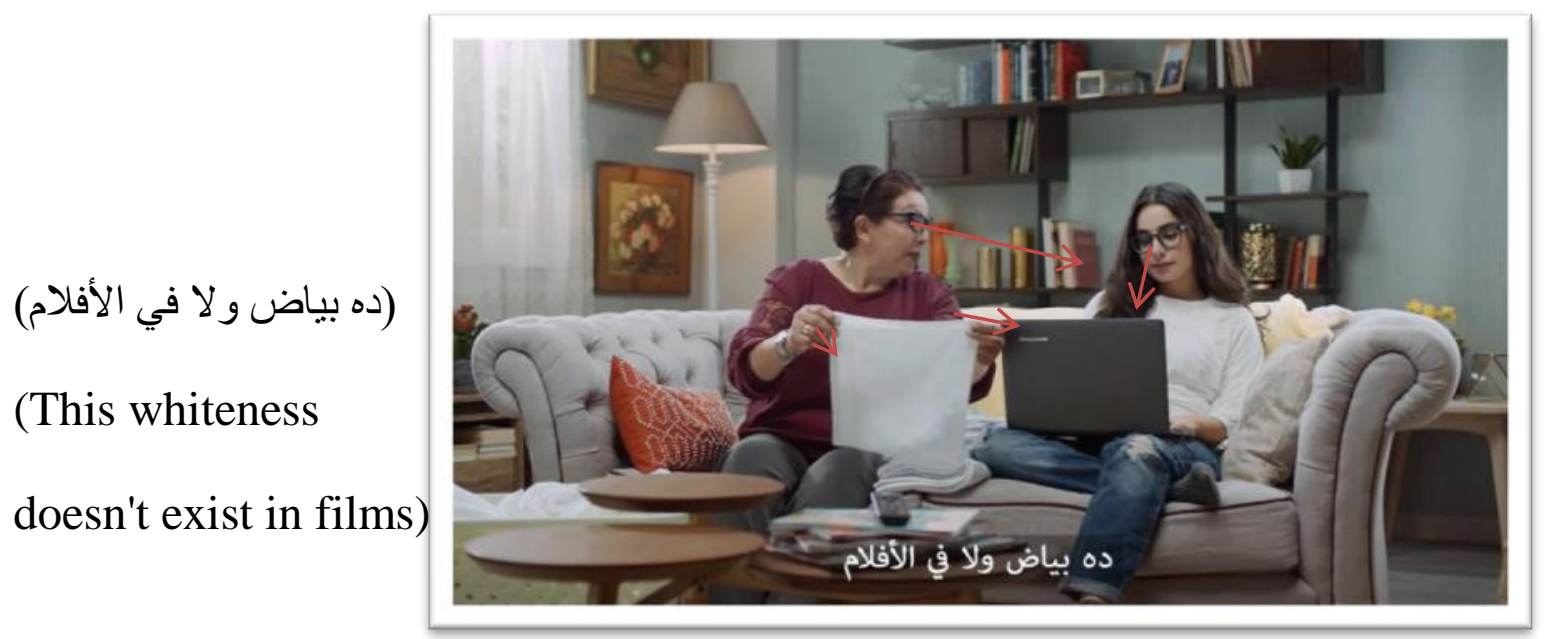

\section{1.The interactive metafunction analysis}

The first shot is an offer image, in terms of the system of gaze, since the two represented participants are not looking at the viewer. In this shot the mother is gazing at her daughter who is staring at her laptop. The mother's facial expression coupled with her gesture reflects her complaint about the negative attitude her daughter takes. Being portrayed in an offer image, the two represented participants are depicted as items of information to be contemplated by the viewer. In this regard, Kress \& van Leeuwen (2006) maintain that the viewer of an offer image is the "subject of the look, and the represented participant is the object of the viewer's dispassionate scrutiny" (p. 119). As regards social distance, the daughter is portrayed with a close shot displaying her head and shoulders. This results in establishing an intimate relationship between her and the viewer. The mother is captured with a medium close shot which shows her at the waist. This helps in creating a social relationship between her and the viewer. In Hall's (1966) terms, the daughter is shown from close personal distance while the mother is shown from far personal distance. From a horizontal angle perspective, this shot is photographed from a slightly oblique angle which signifies detachment. From a vertical angle perspective, this shot is realised by an eye-level angle which creates a sense of equality between the 
viewer and the two represented participants. Utilising an eye-level angle provides a natural scene for the viewer and therefore depicts the attitude of this mother and her daughter as typical of most Egyptian mothers and daughters.

The second shot is also an offer image in which the two represented participants are both looking at the laundry detergent. In this case, there is no contact between these represented participants and the viewer. That is why the viewer's role here is to observe how the mother teaches her daughter to do the washing, and how her daughter responds to her. From the point of view of social distance, both the mother and the daughter are realised by a medium shot in which they are captured nearly at the knees. This signifies an imaginary social relationship between them and the viewer. According to Hall (1966), the mother and the daughter are shown from far personal distance which is suitable for subjects related to personal interest and involvement. From a horizontal angle perspective, the two represented participants are photographed from an oblique angle. In this respect, the viewer is not involved with them. From a vertical angle perspective, the two represented participants are realised by an eye-level angle which reflects equality between them and the viewer.

The third shot is an offer image in which no contact is directly made between the represented participants and the viewer. In this shot the mother is looking at her daughter in an attempt to convince her to change her attitude and pay more attention to the housework. Nevertheless, the daughter has not undergone any change of attitude. This is clearly seen in her gaze at her laptop. Accordingly, the message communicated here is that women of the daughter's age are not concerned with matters related to housework; instead, they are fond of watching movies. Regarding social distance, both the mother and the daughter are captured with a medium long shot in which their full figures appear. This creates a kind of a social relationship between them and the viewer. As Hall (1966) puts it, these two represented participants are shown from close social distance. From a horizontal angle perspective, the mother is viewed from an oblique angle because she is depicted as communicating with her daughter, whilst the daughter is photographed from a frontal angle signifying involvement. From a vertical angle perspective, the two represented participants are realised by an eye-level 
angle whereby the viewer is made to engage in a symbolic relationship of equality with them.

\section{Analysis of Tide USA TV commercial}

This commercial advertises the American washing detergent Studio by Tide. The commercial features mainly three female represented participants. The first is a Canadian actress and writer named Konstantina Mantelos who plays the role of a new employee in a company. She is also depicted as the major represented participant whom the female voice-over describes all through the commercial. She is fit with a light complexion and fairly long straight hair. She is putting on a little make-up with soft pink colours giving her an elegant and relaxing look. Although this is her first day at her new job, she wears a sleeve length fitted red dress which the advertiser considers "a bold move"- the tagline of the commercial. She wears the same red dress the next day, which is perceived to be a bolder move. The second represented participant is a quite slim young woman with brown skin and short curly hair. At the beginning of the commercial she wears a semi-casual outfit in dark colours, but at the end she is dressed in a formal outfit in a white blouse and a black skirt. The third is an old woman with a light skin and long grey hair. Acting as the employer of the company, she is portrayed as wearing classy formal outfits throughout the commercial.

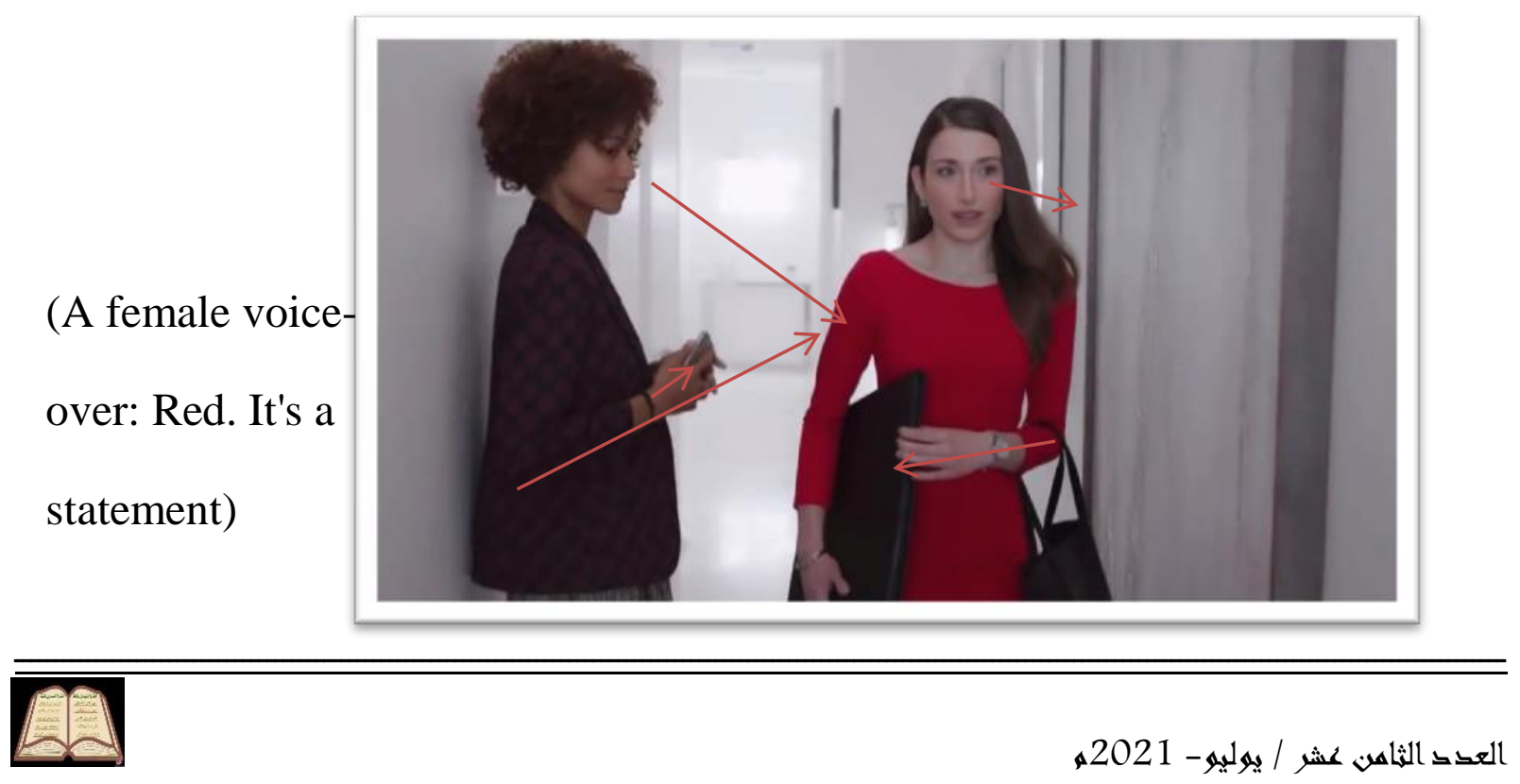



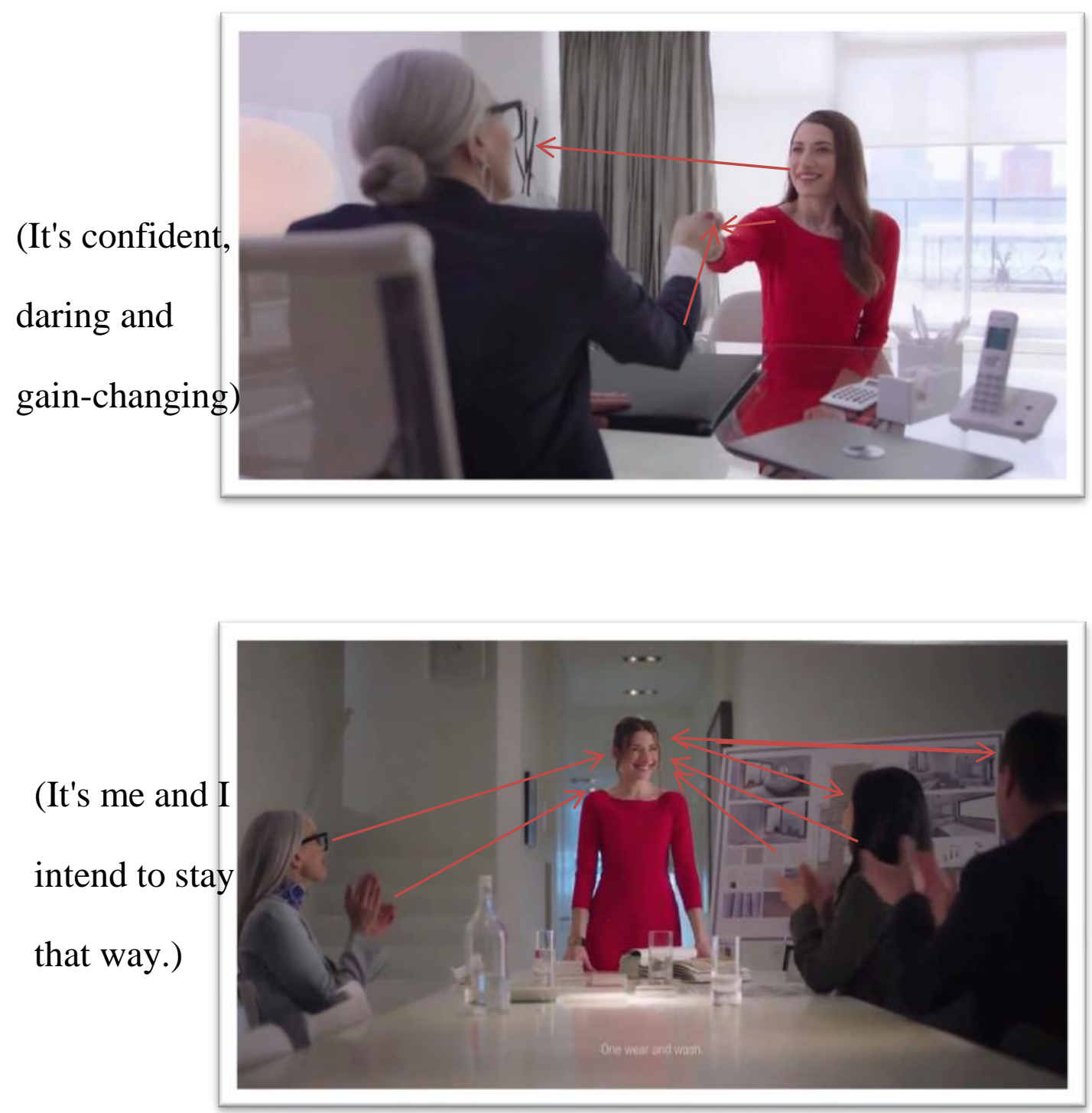


\subsection{The interactive metafunction analysis}

The first shot constitutes an offer because the two represented participants are not making any direct contact with the viewer. In this shot the brown-skinned woman is gazing steadily at the red-dressed woman who is not looking at her. The brown-skinned woman's look signifies her surprise at the red dress the other woman is wearing, whilst the red-dressed woman's glance together with her facial expression reflects her worry. Consequently, in this offer image the viewer is invited to scrutinise the two represented participants in terms of their facial expressions, different outfits and hairstyles. As to social distance, the two represented participants are realised by a medium shot displaying them nearly at the knees. This creates an imaginary social relationship between them and the viewer. In Hall's (1966) terms, this relationship is based on far personal distance. From a horizontal angle perspective, the red-dressed woman is photographed from a frontal angle, whereas the brown-skinned woman is viewed from an oblique angle. Kress \& van Leeuwen (2006) claim that "[t]he horizontal angle encodes whether the image-producer (and hence, willy-nilly, the viewer) is 'involved' with the represented participants or not" (p. 136). In this sense, the producer of this commercial has aligned himself with the light-skinned woman and her bold move, but not with the brown-skinned woman. The viewer is thus made to be involved with the former and detached from the latter. From a vertical angle perspective, the two represented participants have been depicted using an eye-level angle connoting a symbolic equal relationship between them and the viewer.

The second shot is an offer image consisting of two represented participants who are contacting with each other instead of contacting directly with the viewer. In this sense, the viewer's role is to contemplate the two represented participants, especially the red-dressed woman whose gaze and smile illustrate her being confident and successful. Accordingly, the implied message the producer of this commercial communicates to the target audience is that they should take the red-dressed woman's confident and daring attitude which stems from her usage of Tide. Pertaining to social distance, the two represented participants are captured with a medium close shot whereby they are seen at the waist and hence close to the viewer. This connotes an imaginary social 
relationship with the viewer. As maintained by Hall (1966), this relationship relies on far personal distance. From a horizontal angle perspective, the reddressed woman is seen from a frontal angle, whilst the old woman is photographed from behind from an oblique angle. This leads the viewer to be involved with the red-dressed woman and with her self-confidence, and detached from the old woman. From a vertical angle perspective, the two represented participants are viewed from a slightly low angle whereby they appear superior and are given symbolic power over the viewer.

The third shot is an offer image which addresses the viewer indirectly. In this shot the three represented participants are looking admiringly at the reddressed woman who is depicted as the major focus of their attention and appreciation. In addition, the red-dressed woman is gazing in pleasure at her colleagues. In this respect, the message conveyed here is that women should be determined and self-assured like the red-dressed woman who keeps her dress clean by washing it with Tide. As for social distance, the red-dressed represented participant is captured with a medium shot by which she is viewed nearly at the knees. That is why an imaginary social relationship is established between her and the viewer. As Hall (1966) puts it, this relationship is based on close social distance which is familiar to people working together. The other three represented participants are realised by a medium close shot which also forms an imaginary social relationship with the viewer. According to Hall (1966), this relationship draws on far personal distance, for the three represented participants are shown from the waist up. From a horizontal angle perspective, the reddressed woman faces the viewer frontally while the other three represented participants are photographed from behind from an oblique angle. Clearly, the viewer is caused to be centrally involved with the red-dressed woman and with her success. From a vertical angle perspective, the red-dressed woman is seen from a low angle making her look self-assured, imposing and awesome. As cited in Kress \& van Leeuwen (2006), "[1]ow angles generally give an impression of superiority, exaltation and triumph" (p. 140). In this regard, the viewer has to look up to the red-dressed woman who is represented as a symbol of selfconfident, successful women.

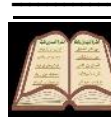




\section{$\underline{\text { Conclusion }}$}

The first commercial presents a stereotypical image of women since it highlights the idea that women's principal task is doing the washing. It also perpetuates the belief that marriage is what concerns most women. This can be realised through the dialogue in the romantic movie the daughter is watching in addition to her mother's recommendation that she learn to do the washing so as to get married. In this respect, the producer highlights the fact that women have to give priority to learning how to do the laundry if they seek marriage. More importantly, the two female represented participants are not positively portrayed in this commercial. First, the daughter is depicted as lazy wasting her time aimlessly eating and watching movies. She is neither helping her mother with the housework nor paying attention to her advice. Second, the mother is portrayed as adopting the traditional thought that her role is to prepare her daughter to marriage by means of teaching her how to succeed in washing her husband's clothes. It can be inferred from this commercial that women's success is closely related to their choice of an effective laundry detergent, such as Tide. Accordingly, this commercial devalues the achievements of women and does not cope with their significant role in today's society.

The second commercial presents a positive image of women by means of giving them active roles. It supports the belief that women can lead, influence and achieve success. First, the old woman, who acts as the manager of the company, sets an example of a good leader who respects her employees and encourages them to achieve success. Second, the major represented participant is shown as the fresh blood, reviving the company and influencing her colleagues. She is presented as a determined, confident woman who is capable of meeting her target easily. Nevertheless, the only brown-skinned woman in this commercial is not assigned an active role compared with the other light-skinned women. She is not seen doing any significant work from the very beginning of the commercial till its end; her role is confined to admiring the red-dressed woman and hence being influenced by her. This highlights the core of the American culture in which the white are given more influential roles than the black.

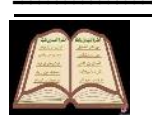


It should be noted that all the represented participants in this commercial are female except for one male represented participant who is photographed from his back and is therefore assigned a peripheral role. In a nutshell, the major female represented participant utilising the advertised product in this commercial is not stereotypically portrayed. Instead of being depicted as doing the daily housework, she is presented as a working woman who is unique, self-assured, ambitious, impressive and successful. In this respect, this commercial provides a positive message for women through instilling confidence into them and urging them to be fearless with their own choices whatever bold these choices may seem in the others' eyes.

\section{$\underline{\text { References }}$}

\section{Primary sources}

Tide Egypt TV commercial [video]. (2017). Retrieved from https://www.youtube.com/watch?v=hRs0AJNpVvA

Tide USA TV commercial [video]. (2019). Retrieved from https://www.youtube.com/watch?v=rMAO_OYowTM

\section{Secondary sources}

Abdel Aziz, A. (2018). Redefining gender representation in selected TV commercials: A multimodal approach. doi: 10.21608/jssa.2018.12140

Dyer, G. (2009). Advertising as communication. London: Routledge.

Gómez, L. (2017). Women's roles and images in advertising: A pragmatic perspective, Cadiz University, Spain. Retrieved from http://rodin.uca.es/xmlui/

Hall, E. (1966). The hidden dimension. New York: Doubleday.

Jewitt, C., \& Oyama, R. (2004). Visual meaning: a social semiotic approach. In T. van Leeuwen \& C. Jewitt (Eds.), The handbook of visual analysis (pp. 134-155). London: SAGE Publications.

Jewitt, C. (2013). Multimodal methods for researching digital technologies. In S. Price, C. Jewitt \& B. Brown (Eds.), The SAGE handbook of digital technology research (pp. 250-265). London: SAGE. 
Jewitt, C., Bezemer, J., \& O'Halloran, K. (2016). Introducing multimodality. New York: Routledge.

Kress, G. (2001). Sociolinguistics and social semiotics. In P. Cobley (Ed.), The Routledge companion to semiotics and linguistics (pp. 66-82). New York: Routledge.

Kress, G., \& van Leeuwen, T. (2006). Reading images: The grammar of visual design (2nd ed.). New York: Routledge.

Kress, G. (2010). Multimodality: A social semiotic approach to contemporary communication. London: Routledge.

Kress, G. (2012). Multimodal discourse analysis. In J. Gee \& M. Handford (Eds.), The Routledge handbook of discourse analysis (pp. 35-50). New York: Rouledge.

Kress, G. (2012). What is multimodality? [Video file]. Retrieved from http://www.youtube.com/nt5wPIhhDDU

van Leeuwen, T. (2005). Introducing social semiotics. New York: Routledge. 